\title{
Metodologia da problematização como estratégia de ensino e aprendizagem na enfermagem
}

\section{Problematisation methodology as a teaching and learning strategy in nursing}

Cíntia Beatriz Goi' • Maicon Machado Sulzbacher² • Eniva Miladi Fernandes Stumm³ • Gerli Elenise Gehrke Herr ${ }^{4}$ Adriane Cristina Bernat Kolankiewicz ${ }^{5}$

\begin{abstract}
RESUMO
Objetiva-se descrever a experiência vivenciada por acadêmicos do curso de enfermagem a partir da implementação da metodologia problematizadora no decorrer do estágio supervisionado em uma Estratégia de Saúde da Família de um município da região Noroeste do Estado do Rio Grande do Sul. Trata-se de um estudo descritivo, tipo relato de experiência a partir da utilização da Metodologia da Problematização no decorrer do componente curricular Estágio Curricular Supervisionado em Enfermagem I. As intervenções propostas pelos acadêmicos instigados pela metodologia em questão foram capazes de melhorar o quadro clínico do usuário, melhorando, ainda, o conhecimento em saúde dos estudantes. Concluí-se que a metodologia utilizada instigou o aprendizado e a tomada de iniciativa dos estudantes, tornando objetiva uma forma de fornecer atenção em saúde de modo mais reflexiva, fazendo-a mais complexa e efetiva.
\end{abstract}

Palavras-chave: Metodologia; Cuidado; Enfermagem.

\begin{abstract}
The aim is to describe the experience by nursing students from the implementation of the problematizing methodology during the supervised internship in a Family Health Strategy of a municipality in the northwest of the State of Rio Grande do Sul. It is about a descriptive study, experience report type from the using of Problematisation Methodology in the course of the curricular component Supervised Curricular Training in Nursing I. The academics interventions proposals instigated for the methodology in question were capable to improve the clinical picture of the usufructuary, improving, still, the knowledge in health of the students. It concludes that the used methodology instigated the learning and the initiative talking of the students, returning objective a form to supply attention in a way more reflective health, making it more complex and accomplished.
\end{abstract}

Keywords: Methodology; Care; Nursing.

${ }^{1}$ Enfermeira. Mestranda do Programa Educação e Formação de adultos na Escola Superior de Educação (Instituto Politécnico do Porto). E-mail: cintiabgoi@bol.com.br ${ }^{2}$ Enfermeiro. Mestrando do Programa de Pós-Graduação em Atenção Integral à Saúde (PPGAIS) da Universidade Regional do Noroeste do Estado do Rio Grande do Sul (UNIJUÍ) Brasil. E-mail: maiconsulzbacher@hotmai.com

${ }^{3}$ Enfermeira Assistencial no Hospital Unimed ljuí /Rio Grande do Sul. Mestranda do PPGAIS da UNIJUÍ. E-mail: gerli.herr@yahoo.com.br

${ }^{4}$ Enfermeira. Doutora em Ciências. Docente da Graduação em Enfermagem e do PPGAIS da UNIJUÍ. E-mail: eniva@unijui.edu.br

${ }^{5}$ Enfermeira. Doutora em Ciências. Docente da Graduação em Enfermagem e do PPGAIS da UNIJUÍ. E-mail: adri.saudecoletiva@gmail.com. 


\section{INTRODUÇÃO}

0 cuidado de enfermagem é considerado essencial na rede de atenção à saúde. As equipes estruturantes necessitam de qualificação em diversas áreas que se complementam, a fim de ofertar o cuidado integral. 0 cuidado integral baseia-se em ações de promoção, prevenção de agravos, tratamento e reabilitação de saúde. Engloba a escuta, o acolhimento com tratamento digno e respeitoso, devendo olhar o ser humano como um todo, substituindo o foco da doença pela atenção à pessoa, abrangendo sua história de vida, modo de viver e até mesmo o de adoecer, satisfazendo o paciente nas suas necessidades de atenção à saúde ${ }^{1}$.

O Conselho Nacional de Educação/ Câmara de Educação Superior (CNE/CES) estabelece, em sua última diretriz para formação dos profissionais de enfermagem, que se deve assegurar que sua prática seja realizada de forma integrada e contínua com as demais instâncias do sistema de saúde, sendo capaz de pensar criticamente, de analisar os problemas e procurar soluções para os mesmos, não somente "preso" ao aprendizado das técnicas de responsabilidade do profissional, porém procurando uma formação generalista, humanista, crítica e reflexiva².

As instituições formadoras, necessitam adotar práticas pedagógicas inovadoras em suas práticas de ensino e assistência. Quanto a metodologias de ensino e aprendizagem, a Metodologia da Problematização (MP), que tem sua gênese baseada em documentos descritos por Charles Maguerez (1966) é uma das metodologias ativas frequentemente usada ${ }^{3}$. Aspectos da MP resultam em reflexões emanadas da prática e sinalizam as potencialidades e limitações deste método como ferramenta no ensino da enfermagem ${ }^{4}$.

A estrutura do Arco de Maguerez utilizada na MP permite observar a realidade vivenciada, reflexões, teorizações, sugerir hipóteses de solução a fim de transformar a realidade ${ }^{5}$. Desta maneira, é possível uma integração entre o ensino/serviço, compreendendo o trabalho coletivo entre gestores e trabalhadores da saúde juntamente com docentes e alunos. A proposta de metodologia é centralizada no aluno e na realidade. A necessidade de construção de conhecimentos específicos, aplicação dos resultados da pesquisa na prática deve ser um foco da graduação em enfermagem ${ }^{1,5}$.

A partir deste contexto, o objetivo deste estudo foi descrever a experiência vivenciada por acadêmicos do curso de enfermagem a partir da implementação da metodologia problematizadora no decorrer do estágio supervisionado em uma Estratégia de Saúde da Família de um município da região Noroeste do Estado do Rio Grande do Sul.

\section{MÉTODO}

Trata-se de um estudo descritivo, tipo relato de experiência a partir da utilização da MP no decorrer do componente curricular Estágio Curricular Supervisionado em Enfermagem I, que tem como objetivo desenvolver as habilidades e competências gerais inerentes ao enfermeiro, desenvolvido por acadêmicos do Curso de Enfermagem da Universidade Regional do Noroeste do Estado do Rio Grande do Sul (UNIJUÍ), em uma Estratégia de Saúde da Família (ESF), supervisionado por docentes enfermeiros.

A prática foi realizada em uma ESF localizada em um município na região Noroeste do Estado do Rio Grande do Sul. As atividades foram desenvolvidas no primeiro semestre de 2016, sendo planejado o desenvolvimento da MP a partir da realidade vivenciada. A ESF em que foi realizado o estágio supervisionado tem sua população adscrita aproximadamente de 5.200 pessoas na sua área de atuação.

As atividades foram desenvolvidas com carga horária de 210 horas em atividades práticas, e a cada 15 dias foram realizados socializações e aprofundamento teórico na universidade. A participação na atividade curricular foi de 11 estudantes divididos em 4 duplas e um trio, cada dupla ou trio ficou em estágio em uma ESF.

Os acadêmicos foram desafiados a desenvolver a MP3 sendo instigados a: realizar a observação da realidade, fazer levantamento de problemas; elencar os pontoschave refletindo a respeito do problema; em seguida, realizar a teorização procurando buscar informações e conhecimentos sobre o problema; posterior a estas etapas, realizar o levantamento de hipóteses e soluções, a fim de buscar elementos para elaboração de possíveis soluções; e, por último, aplicar a prática à realidade que possibilita a intervenção, o exercício e o manejo das situações. Destacase que, após a observação da realidade e o levantamento de problemas, os estudantes elegeram um problema para descrever suas etapas em sua totalidade e aplicar à realidade.

\section{RESULTADOS E DISCUSSÃO}

Inicialmente, as docentes da disciplina apresentaram o plano de ensino e refletiram com os estudantes as ações representativas de cada uma das etapas da MP com o Arco de Maguerez. Para a realização da proposta, foram seguidos os passos da MP que se dividem em cinco etapas: observação da realidade; identificação dos problemas, pontos-chave; teorização; hipóteses de solução; planejamento e aplicação - execução da ação (prática) ${ }^{3,5}$.

Deparando-se com o cotidiano de uma ESF na sua área adstrita, foram identificados vários problemas, e os estudantes foram instigados a observar, refletir e propor ações para mudanças. Primeiramente, os acadêmicos conversaramcomaequipee explicaramqueimplementariam a metodologia ativa do tipo problematizadora, pois a principal característica dessas metodologias é inserir o acadêmico como agente principal na construção de seu aprendizado. Sendo assim, os estudantes explicaram cada etapa e a forma como colocariam em prática. 
A seguir serão descritas as etapas vivenciadas na realidade pelos estudantes.

\section{Primeira etapa: observando a realidade}

Na primeira etapa, é necessário realizar a observação da realidade ${ }^{3}$ com a participação ativa dos estudantes de enfermagem, funcionários da ESF e usuário em questão. Neste momento, os acadêmicos foram orientados pelos docentes para que observassem com atenção e registrassem de forma sistematizada suas percepções com foco aos problemas.

Foi realizado um olhar minucioso em cada situação vivenciada na unidade de saúde e identificado como problema a dificuldade de cicatrização das lesões por pressão, situação essa apresentada por um usuário pertencente à ESF do local das práticas. O usuário do estudo é cadeirante há 22 anos pós-trauma por queda do telhado de sua residência, ocasionando paraplegia por Lesão Medular Espinhal (LME) (T12); mora sozinho, em precárias condições de higiene pessoal e residencial, apresenta prolapso em ostomia de colón descendente com $13,5 \mathrm{~cm}$ de comprimento e faz uso de sonda vesical de demora aberta em bolsa coletora em sistema fechado, apresenta lesões por pressão grau III, apresentando fibrina nas bordas das lesões em região do cóccix e glúteo máximo interno esquerdo, apresentando secreção purulenta e fétida em grande quantidade, sendo ocluído com a cobertura de Rifamicina Spray.

Tabela 1. Medidas das feridas na região do cóccix e glúteo máximo interno esquerdo do usuário antes de qualquer intervenção, RS. 2016

\begin{tabular}{l|c|c|c}
\hline \multicolumn{1}{c|}{ Região } & $\begin{array}{c}\text { Profundidade } \\
\text { (cm) }\end{array}$ & $\begin{array}{c}\text { Comprimento } \\
\text { (cm) }\end{array}$ & $\begin{array}{c}\text { Área total } \\
\text { (cm2) }\end{array}$ \\
\hline Coccígea & 3 & 4 & 12 \\
\hline $\begin{array}{l}\text { Glúteo máximo } \\
\text { interno } \\
\text { esquerdo }\end{array}$ & 2,5 & 6 & 15 \\
\hline
\end{tabular}

Fonte: elaboração própria.

O problema foi identificado ao longo das atividades práticas, sendo que o mesmo servirá para adquirir conhecimento tanto em âmbito clínico quanto psicossocial, com possibilidade de aplicar o conhecimento teórico adquirido ao longo da formação acadêmica.

\section{Segunda etapa: identificando os pontos-chave}

Nessa etapa, os acadêmicos refletem a respeito do problema, identificam possíveis fatores associados e determinantes que afetam o contexto no qual o problema ocorre. Após toda essa reflexão, extrai-se o sentido para o estudo, pelas possíveis explicações da existência do problema. A partir daí, são elencados os pontos-chave ${ }^{3,5}$. Elaboraram-se as hipóteses explicativas, a partir dos conhecimentos prévios.
Foram elencados pelos estudantes, quanto ao problema das úlceras crônicas do usuário, os seguintes pontos-chave: cobertura inadequada das lesões por pressão; nutrição inadequada e cadeirante por paraplegia.

Esta fase da problematização permitiu aos estudantes uma reflexão acerca das causas e fatores determinantes no seu contexto de trabalho, permitindo a definição dos possíveis temas a serem trabalhados, pontuando, dessa forma, as prioridades e metas a serem atingidas ${ }^{6}$.

\section{Terceira etapa: teorização}

$\mathrm{Na}$ terceira etapa, elege-se a forma de estudar os pontos-chave. Os acadêmicos se organizam para buscar conhecimento e aprofundamento sobre o problema em fontes científicas, as informações levantadas são organizadas, analisadas e discutidas para propor possibilidades de solução do problema e o registro é necessário para o desenvolvimento da etapa seguinte ${ }^{5}$.

Portanto, a cobertura inadequada na lesão é um ponto importante no cuidado com este paciente. A ferida avaliada pelos acadêmicos apresentava grande quantidade de secreção purulenta. A mesma estava recebendo a cobertura de rifamicina, modo spray. $\mathrm{O}$ uso de rifamicina, assim como outros antibióticos de ação local, pode apresentar interferência no processo cicatrização, assim como possibilita o risco de desenvolver resistência bacteriana e hipersensibilidade ${ }^{7}$. Sendo assim, a aplicação de rifamicina é contra-indicada tanto em feridas abertas, como a do usuário em questão.

Outro fator observado que contribui negativamente no processo cicatricial é a alimentação inadequada, visto que o paciente realiza apenas as refeições do almoço, café da manhã e jantar, sendo que, nas duas últimas citadas, apenas alimenta-se de bolachas. Portanto deve-se rever quanto aos fatores nutricionais e hídricos, pois pacientes que apresentam déficits desses fatores podem acarretar perda de massa muscular e peso, tornando os ossos mais proeminentes; o edema e a diminuição do fluxo cutâneo também acompanham esses déficits, resultando em lesões isquêmicas, contribuindo no desenvolvimento das lesões por pressão ${ }^{8,9}$. Além disso, é necessária uma dieta adequada para que haja eficácia no processo cicatricial, já que as células que formam nossa derme são constituídas por substâncias encontradas também na alimentação, como proteínas e lipídeos ${ }^{10}$.

O usuário reside sozinho, e a cadeira de rodas limita seu espaço, dificultando suas atividades diárias, o que ocasiona, por vezes, a permanência na mesma posição agravando o estado das lesões. Portanto, ser cadeirante se torna mais um fator de risco para o aparecimento de lesão por pressão. As feridas ocorrem em pessoas que fazem uso de cadeira de rodas ou acometidas ao leito, pois, ao permanecerem na mesma posição por muito tempo, o apoio de sustentação causa uma pressão local, acarretando um constante processo isquêmico, podendo ser caracterizado por áreas de necrose tecidual ${ }^{9}$. 
As temáticas levantadas anteriormente potencializam as lesões por pressão. Essas lesões apresentam etiologia multivariável, na qual o paciente está exposto como estado geral da pele em risco, perfusão e oxigenação, estado nutricional, aumento da umidade da pele, idade avançada, percepção sensorial e estado geral de saúde ${ }^{9}$. Nesse contexto, a teorização procurou construir as respostas referentes ao problema.

\section{Quarta etapa: hipóteses de solução}

A partir do aprofundamento teórico, buscaram-se elementos para a elaboração de hipóteses para possíveis soluções de forma criativa e crítica ${ }^{6}$. Foram definidas as seguintes hipóteses:

Mudança da cobertura da ferida: é importante a troca da cobertura para agilizar/contribuir com o processo de cicatrização, fator que irá reduzir e prevenir complicações.

Melhora do desempenho nutricional: está bem esclarecida na literatura a importância de um balanço nutricional adequado para que ocorra uma cicatrização ideal.

Encaminhamento à Unidade de Reabilitação (UNIR): com o encaminhamento para UNIR, o paciente poderá trocar a cadeira de rodas, adquirir uma cadeira para realizar sua higiene pessoal e fará acompanhamentos com equipe multiprofissional.

\section{Quinta etapa: aplicação prática á realidade}

Na última etapa, foi colocado em prática o conhecimento construído. Ao seguir esse caminho, os acadêmicos devem tomar decisões e executá-las, elegendo critérios para a aplicabilidade ${ }^{5}$.

A avaliação, discussão e mudança no tratamento das lesões foram realizadas por meio das reflexões teórico-práticas, com a proposta e utilização de nova cobertura. Atualmente, utiliza-se Kollagenase, nas bordas desvitalizadas, para que a enzima colagenase que detém o princípio ativo da cobertura desintegre estes tecidos, o que possibilita o surgimento de tecido de granulação ${ }^{10}$. Foi utilizado como cobertura nas lesões, e para prevenção, Ácidos Graxos Essenciais (A.G.E.), o que permite que o tecido de granulação existente se prolifere. O mesmo ocorre porque A.G.E. têm em sua composição vitaminas como A e E; Ácido Linelóico que promove a ângiogênese; triglicerídeos de cadeia média, que funcionam como emoliente; e Lecitina que auxilia na formação da membrana celular, já que a mesma consiste em lipídeos. A forma de bicamada lipídica é composta a membrana celular ${ }^{10,11}$.

O curativo foi realizado pelos estudantes uma vez ao dia, de segunda à sexta-feira. Aos finais de semana, o mesmo foi realizado pelo filho do usuário conforme orientações dos acadêmicos de enfermagem. Após um período de oito semanas, com a troca da cobertura, observou-se as seguintes medidas:
Tabela 2. Medidas das feridas na região do cóccix e glúteo máximo interno esquerdo do usuário antes da intervenção, RS. 2016.

\begin{tabular}{l|c|c|c}
\hline \multicolumn{1}{c|}{ Região } & $\begin{array}{c}\text { Profundidade } \\
\text { (cm) }\end{array}$ & $\begin{array}{c}\text { Comprimento } \\
\text { (cm) }\end{array}$ & $\begin{array}{c}\text { Área total } \\
\text { (cm2) }\end{array}$ \\
\hline Coccígea & 1,4 & 2,8 & 3,92 \\
\hline Glúteo & 1,5 & 4,3 & 6,45 \\
\hline
\end{tabular}

Fonte: elaboração própria.

Foi observada a diminuição da secreção e melhora no processo cicatricial, sendo que a ferida na região coccígea obteve uma melhora na cicatrização de $67,3 \%$, e a região glútea máxima interna esquerda $57 \%$ desde as intervenções dos acadêmicos. O acompanhamento nutricional e a introdução de complemento foram realizados pela nutricionista local da ESF e por acadêmicos do curso de Nutrição da mesma universidade, através do estágio integrado realizado no componente, onde acadêmicos dos cursos de enfermagem e de nutrição discutem quinzenalmente o caso do usuário.

O próximo encaminhamento foi à UNIR, serviço esse que, conforme a Portaria $n^{\circ} 793$ de 2012, institui a rede de cuidados a pessoas com deficiência no âmbito do Sistema Único de Saúde (SUS) ${ }^{12}$. Esta portaria oportuniza diversos tipos de materiais e equipamentos, dispondo de uma equipe multidisciplinar especializada no atendimento destes usuários, tanto em atividades ambulatoriais como para acompanhamento e dispensação de Órteses, Próteses e meios de locomoção auxiliares (andador, muleta, cadeira de rodas, cadeira de banho, bengala), tendo em vista que muitos usuários têm demandas específicas e vulnerabilidades sociais ${ }^{13}$.

Na formação acadêmica, ao docente são ofertadas novas possibilidades de orientar sua prática profissional, por meio da reflexão e do uso de metodologias ativas, dotado do conhecimento científico que embasará a formação de novos enfermeiros ${ }^{14}$. A mudança de cobertura foi explicitada à equipe de enfermagem da ESF que realizava o curativo ao longo do tempo e ao paciente, sendo demonstrado a ambos o porquê da mudança e a efetividade da mesma. A reflexão ao longo do estágio foi constante entre docentes e discentes, possibilitando ao graduando pensar sobre o saber adquirido e sua aplicação na pratica, de maneira a favorecer a práxis de enfermagem

\section{CONCLUSÃO}

Com o estudo descrito por meio da MP, os acadêmicos conseguiram identificar problemas vivenciados pelo usuário sendo propositivos com intervenções, obtendo progresso na cicatrização das feridas. A metodologia foi efetiva também quanto à melhora na capacidade de desenvolvimento de conhecimento científico, o que possibilita a acadêmicos de enfermagem obter uma formação reflexiva mostrando a capacidade do "olhar" de enfermagem seguido de medidas críticas com proposições 
de modificação de uma rotina de cuidados, para estabelecer a melhor forma para uma intervenção, por meio das medidas propostas e realizadas pelos acadêmicos, que receberam o reconhecimento da sua efetividade pela equipe da ESF e usuário. A partir desse contexto, a MP foi positiva para os sujeitos envolvidos, equipe da ESF, acadêmicos e o usuário.

\section{REFERÊNCIAS}

1. Costa CR, Fontoura EG, Servo MLS, Rosa DOS. The meaning of caring/care under the view of the nursing students. J Nurs UFPE line [Internet]. 2012; 6(1):149-55. Disponível em: http:// www.revista.ufpe.br/revistaenfermagem/index.php/revista.

2. CNE/CES. Diretrizes Curriculares Nacionais dos Cursos de Graduação em Enfermagem, Medicina e Nutrição. [Internet]. 2001 [cited 2016 Jun 7]. Disponível em: http://portal.mec.gov. br/dmdocuments/ces1133.pdf

3. Maguerez C. La promotion technique du travailleur analphabete. Éditions d'Organisation, editor. Paris; 1966.

4. Schaurich D, Cabral FB, Almeida MDA. Metodologia da problematização no ensino em Enfermagem: uma reflexão do vivido no PROFAE / RS. Esc Anna Nery [Internet]. 2007; 11(2):318-24. Disponível em: http://www.scielo.br/pdf/ean/ v11n2/v11n2a21.

5. Vieira MNCM, Panúncio-Pinto MP. A Metodologia da Problematização (MP) como estratégia de integração ensinoserviço em cursos de graduação na área da saúde. Med (Ribeirão Preto) [Internet]. 2015; 48(3):241-8. Disponível em: http://www.revistas.usp.br/rmrp/article/view/104310.

6. Zuge SS, Padoin SM de M, Brum CN de, Tronco CS. A metodologia problematizadora na prevenção de acidentes em central de material e esterilização. Cogitare Enferm [Internet]. 2012; 17(1):162-5. Disponível em: http://revistas. ufpr.br/cogitare/article/viewFile/26392/17585.

7. Oda RM, Salotti SRA, Guimarães HCQCP. 3.14 Manual de Normas, Rotinas e Técnicas de Curativos.pdf. Centro de Estudos “Dr. Reynaldo Quagliato," editor. Bauru - SP; 2004.13 p.

8. Verdú J, Estrella Perdomo. Nutrição e Feridas Crónicas. 12th ed. GNEAUPP, editor. Logroño; 2011. 55 p.

9. NPUAP/EPUAP/PPPIA. Prevention and Treatment of Pressure Ulcers: Quick Reference Guide. Clinical Practice Guideline [Internet]. 2014 [cited 2016 July 01]. 1-75 p. Available from: https://www.npuap.org/wp-content/uploads/2014/08/ Updated-10-16-14-Quick-Reference-Guide-DIGITAL-NPUAPEPUAP-PPPIA-160ct2014.pdf

10. Guyton AC, Hall JE. Tratado de Fisiología médica. Vol. 12, Elsevier. 2010.1092 p.

11. Brasil. Ministério da Saúde do Brasil. Procedimentos. Cadernos de Atenção Primária, n. 30. Brasília [Internet]. 2011 [cited 2016 July 01]. Available from: http://189.28.128.100/dab/ docs/publicacoes/cadernos_ab/abcad30.pdf

12. Brasil. Ministério da Saúde. Portaria $N^{\circ} 793$, de 24 de abril de 2012. Institui a Rede de Cuidados à Pessoa com Deficiência no âmbito do Sistema Único de Saúde. Brasília (DF): Ministério da Saúde; 2012.

13. Trombetta AP, Ramos FRS, Vargas MA de O, Marques AMB. Singularities work of a rehabilitation center under the perspective of the healthcare team. Esc Anna Nery-Rev Enferm
[Internet]. 2015 [cited 2016 July 05];19(3):446-53. Available from: http://www.gnresearch.org/doi/10.5935/14148145.20150059

14. Rodrigues IDCV, Santos VEP, Feijão AR, Silva BCO da, Neto VL de S, Silva RAR da. $O$ ensino de enfermagem a luz da dialética marxista: uma reflexão acerca da prática pedagógica. Rev Atual Enferm Derme [Internet]. 2016 [cited 2016 July 03];76:43-6. Available from: http://inderme.com.br/revistas/revista_14.pdf 